\title{
Innovation indicators in the context of Romanian SMEs: A research agenda
}

\author{
Ioana Alexandra Onea \\ Bucharest University of Economic Studies, Bucharest, Romania \\ ioana_alexandra_o@yahoo.com
}

\begin{abstract}
The purpose of this paper is to present an overview of the theoretical connection between key terms such as innovation indicators and entrepreneurship, highlighting the main trends of innovative activities and practices in the context of Romanian small and medium enterprises. Innovation management has gained an increased interest nowadays since it provides tools for creating competitive advantage and economic growth for enterprises. In this sense, at global and European Union level, innovation indicators have been identified in order to measure the efficiency of innovation. In addition, innovation and entrepreneurship have been connected by scholars, since their application provides business opportunities. Starting from the Europe 2020 Strategy that has innovation as a pillar for reaching economic growth, the present study provides a descriptive analysis of the Regional Innovation Scoreboard 2019 report, followed by a comparative analysis of the European Innovation Scoreboard reports published in the last 5 years. The present paper contributes to the existing knowledge regarding the actual application of innovation indicators in Romanian SMEs. The paper provides an answer to the research questions, which focus on depicting what are the exact innovation indicators that characterize the activities of Romanian SME and what are the trends and weaknesses in the actual business environment in terms of innovative endeavors. This paper provides some recommendations in terms of improvement of innovative efforts for the enterprises that operate in the Romanian market.
\end{abstract}

Keywords: innovation management, innovation indicators, entrepreneurship, SMEs (small and medium enterprises).

\section{Introduction}

Providing a general definition for innovation that can be applied to most economic sectors has been a constant preoccupation for scholars (Gault, 2018). Starting from the idea that innovation and economic growth are closely interlinked, as stated in a research performed on OECD (Organisation for Economic Co-operation and Development) countries (Pradhan et al., 2017) and undergoing the development of several frameworks for portraying an exact definition, innovation can be considered a broad concept that refers to the improvement or the adoption of a new processes, products or organizational methods. These general definitions that refer to product, production/delivery, organizational/marketing innovations are useful when creating a standard that facilitates the data collection and the interpretation of statistics regarding these aspects (Gault, 2018). Moreover, innovation can be considered an "umbrella term" that has implications in several sectors, such as technological, business related, social and cultural (EdwardsSchachter, 2018).

In the last decades, the focus has been on the cultural and social component of innovation and, in this sense the connection with entrepreneurship in both economic and social development has been made. Small and medium enterprises (SMEs) and their efforts towards an innovative approach has been scrutinized in order to establish the adoption of innovative approaches in organizations and the subsequent performance drivers (Turro et al, 2014). Moreover, the connection between entrepreneurship and innovation has been stated in the research performed by $\mathrm{Wu} \&$ Huarng (2015), which emphasized the role of innovation in terms of competitive 
advantage and value creation. Consequently, the question that arises is how to measure the effects of innovation and what indicators should be used. This concern affects all the actors involved in the innovation process, from organizations that need to evaluate their performance to policy makers that need to determine the advancement of subsidized projects (Dziallas \& Blind, 2019). Generally, an indicator is considered to be an assessment of a certain matter, that can be further used in order to create a general framework that measures a specific phenomenon. In the literature, there have been identified multiple types of indicators with different classifications (Dziallas \& Blind, 2019). Although the tendency has been a focus on mostly technical aspects and $R \& D$ activities performed by organizations, thus creating an "R\&D based-innovation paradigm", lately, "non-technological forms of innovation" started achieving more and more importance (Hervas-Oliver et al., 2011). However, the literature fails to present a universal framework followed by a specific set of indicators that could offer an overview of the strengths and weaknesses on which companies should focus in order to drive innovative approaches. Moreover, in addition to the lack of measurement strategy, there is the idea that the indicators provided so far by academics do not offer a solid practical implication (Dziallas \& Blind, 2019).

\section{Literature review}

\section{The relationship between innovation and entrepreneurship}

When focusing on the quality of life, social development has always been connected with entrepreneurship. Moreover, in order to reach a sustainable development, innovative efforts are gaining more and more interest. There have many efforts in trying to establish methods that could help achieve the objective of sustainable development. In this sense, many parties at different levels are being identified to have significant roles, namely "economic, human, environmental and technological systems" in countries, organizations and institutions. Thus, irrespective of the local, regional, national or global levels, entrepreneurship has been closely considered an important part of sustainable development and "societal transformation". Moreover, there have been identified several classifications of entrepreneurship, that define a different perspective of this concept, namely social entrepreneurship, environmental-oriented entrepreneurship and institutional-oriented entrepreneurship. Researchers identify a broad term, namely social entrepreneurship that encompasses all the definitions and directions that aim to "address the contribution of entrepreneurial activities" (Kardos, 2012). Entrepreneurial endeavors are considered to be a key part of the economical development and are closely connected with innovative approaches. Generally, innovation is considered to be identified more with technological progress and disruptive technologies. This is due especially to the fact that innovation is considered a main source of competitive advantage (Fonseca et al., 2020). However, there are many types of innovation according to the effects produced: "imitative innovation"- considered to provide benefits when addressing the improvement of existing products, "sustainable innovation"- considered for the benefits provided in terms of non-technical approaches and "disruptive innovation"- that addresses benefits in terms of products or processes completely new to the market (Talmaciu, 2012).

In the European context, the number of small and medium enterprises (SMEs) is increasing, since these represent a source of employment and economic growth. The European Union (EU) supports the establishment of such business by adjusting policies in order to motivate them to innovate. The literature presents these undertakes from the EU that result in prizes and other benefits for such organizations. Despite these benefits, however, SMEs face difficulties

DOI: $10.2478 /$ picbe-2020-0015, pp. 149-158, ISSN 2558-9652| Proceedings of the $14^{\text {th }}$ International Conference on Business Excellence 2020 
when it comes to applying innovative ideas and this is caused especially to scarce resources and limited financial capabilities. Therefore, the concept of Open Innovation is gaining more and more attention from scholars, since it emphasizes the importance of collaboration between organizations, thus becoming a "need for SMEs". The positive results of this concept are especially evident to small businesses, because of their flexibility and adaptation in business models. When it comes to business model innovation, SMEs can engage in alternative approaches in order to benefit from the overall collaborative approach that represents the basis of open innovation (De Marco et al., 2020).

For the case of Romania, innovation became a "real issue after the accession to EU". The EU2020 Strategy has made its impact on most of the regions from Romania. The challenges and transitions involved in order to adopt an innovative approach are still a barrier for Romania in reaching the title of innovator. In the official report, the country presents as a modest innovator. An exception, however, is represented by the București-Ilfov region, that portrays efforts to slowly become a moderate innovator (Dodescu \& Chirilă, 2012).

\section{Innovation outputs and outcomes}

The efforts of developing innovative approaches are to be measured through innovation performance framework. As previously mentioned, the literature failed to develop a general framework that could measure innovation on all economic sectors. However, there have been identified several indicators that could be used in order to evaluate the input and output in terms of organizational activities. These refer both the products and processes. In terms of innovation inputs, these are connected to the introduction of several products, processes or marketing activities that could result into efficient outputs. However, although connected with the innovative inputs, the literature identified primarily outputs as key indicators for performance measurement. This is due primarily because outputs can have both technological implications or not. When addressing the EU 2020 Innovation Indicator, the measurement of innovative outputs is of crucial importance and it is mostly connected with the patent data resulted from R\&D processes. In this sense, the focus falls on the technological aspect and the "knowledge intensity", which can lead to the upgrade of the sectors involved and the overall improvement of economy (Janger et al., 2017).

In addition, the before mentioned improvement leads to a differentiation between radical innovation and incremental innovation. Although radical innovation may lead to "higher productivity and growth effects", incremental innovation may prove to be just as useful in terms of outputs, if performed frequently. Considering this, the EU 2020 Innovation Indicator has its limitations, as stated by Janger et al. (2017). Therefore, the authors propose two possible measurements of innovation outputs, namely the structural change and the structural upgrading. By doing this, the two frameworks cover both the growth in added value, as well as the "differential performance of firms" (Janger et al., 2017).

A classification of both innovation inputs and outputs is presented by Cavdar \& Aydin (2015). The authors provide a clear classification of what these indicators represent. 


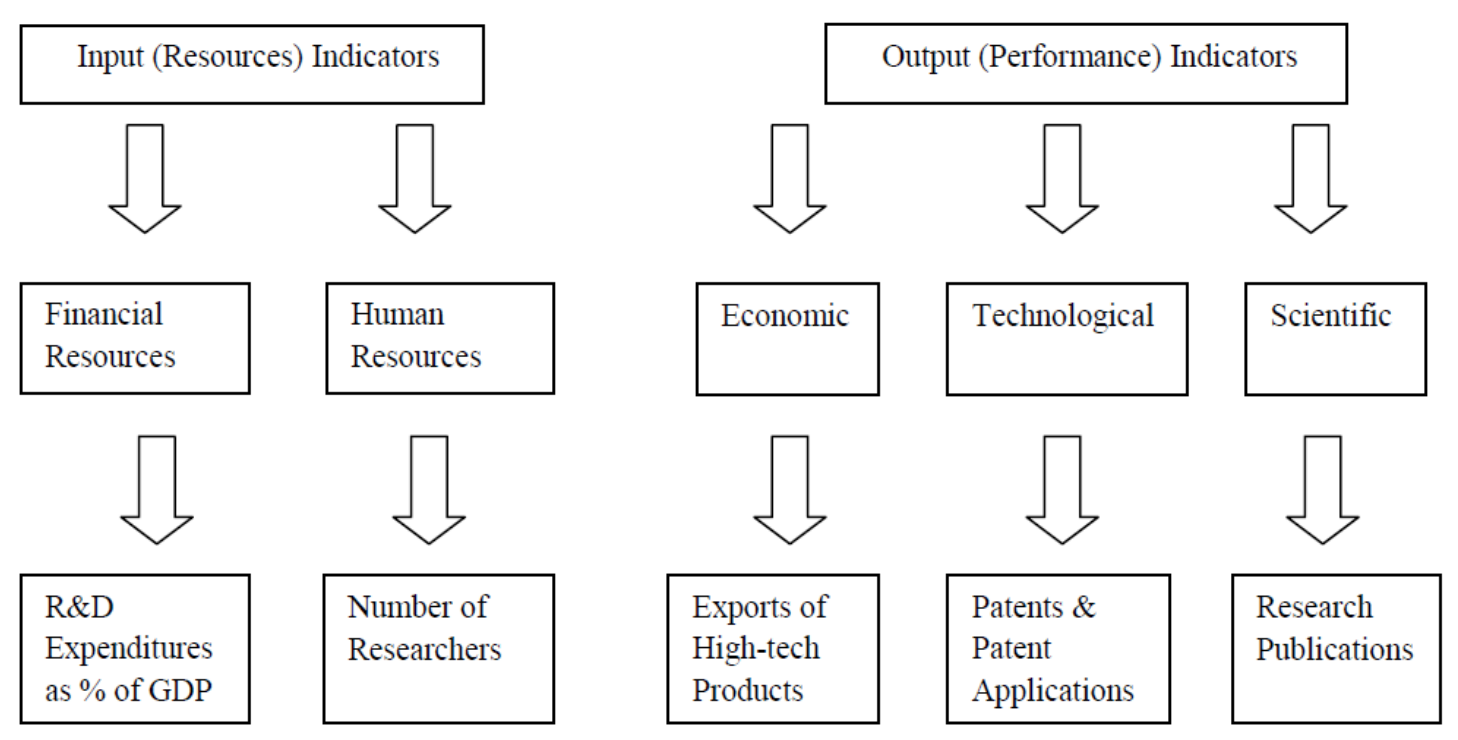

PICBE | 152

Figure 1. Input and output indocators

Source: Cavdar \& Aydin (2015) - An Empyrical Analysis about Technological Development and Innovation Indicators

From the figure below, practical implications and results of the application of such indicators can be deducted. Moreover, even is SMEs do not dispose of the financial resources of big corporations and despite their scarce resources, innovation through development of new products or customizations of existing ones can make the difference between success and failure (Genc et al., 2019).

\section{Indicators of innovation}

When addressing the issue of establishing indicators as a metric for innovation or for measuring performance, there is still a debate of whether these indicators can be applied in order to create a general framework. The matter of innovation performance and the difference between innovative and non-innovative organizations are of crucial importance nowadays (Hashi \& Stojcic, 2013).

In the European context, where the tendency is towards a focus on technological innovation and economic growth, the European Commission has published several official reports that depict metrics on innovations. Such indicators are grouped into four categories: framework conditions, investments, innovation activities and impacts (RIS 2019, published by the European Commission). Therefore, the report assesses the metrics on which innovation can be measured and develops a focus on the implications that reside from this approach. The category "Innovation activities" points out an interesting topic that has been emphasized in the literature as well. In the subcategory, linkages, the collaboration between SMEs is highlighted. In the literature, the "cooperation and coordination across businesses" is highlighted to be an important aspect when measuring firm performance. By applying collaboration, companies can foster innovation, by transferring knowledge and creating creative teams that can work together towards delivering radical innovation (Haneda \& Ito, 2018). This concept has as basis the open innovation concept, that focuses on creating partnerships and exchanging ideas with external partners. In this regard, companies can develop a wide range of activities that contain both input and output innovators and explore knowledge (Cheng \& Huizing, 2014). 
Furthermore, in recent year, the focus has been on those indicators that are not material based, namely the intangible assets. Different from the expenditures and the consequences of the research and development related indicators, the intangible assets as indicators refer more to the organizational capabilities of firms and can be considered as part of the input indicators. In addition, the ability to networking has been identified as a valuable indicator, as part of the efforts undertaken by companies in order to foster collaboration. This set of indicators prove to be especially valuable at a regional level, since the collaboration between firms and the exchange in knowledge fosters a strategic approach toward innovation. Moreover, firms can build up their competitive advantage and their effectiveness through the interaction with all the actors involved in the process. Fostering the creation of intelligent working structures through consolidation of local capabilities represents a critical part of the overall process (Kramer et al., 2011). Literature proves that these types of indicators are applicable especially to the context of SMEs, since their capacity to innovate and the type of innovation should be taken into consideration. It becomes evident the fact the radical innovation can be applicable to established organization, while to small firms innovation development can be evident in their overall business practices, such as customer collaboration and process optimization (Forsman, 2011).

While the organization of overall innovative activities and endeavors may be different from organization to organization, it is true that in the case of SMEs, the association of both inputs and outputs should be carefully managed. Many studies explore the business opportunities of SMEs output, which are related to the R\&D process and product development. However, it has become a reality nowadays the importance of inputs in terms of innovative efforts, especially those that are organization related and impact the financial performance. There are many factors that SMEs should take into consideration when developing strategies for innovation, and probably the most important ones are the possible barriers in terms of scarce resources and uncertainties. Therefore, researchers recommend that the focus should be placed on the overall operational efficiency and in this sense, the company size, age and even business sectors are to be considered. In terms of innovation indicators, what applies for small firms are the behavioral characteristics. The advantages of such firms are represented by their flexibility and adaptability and studies show that these firms are more prone to improve products or processes, meaning adopting incremental innovative approaches, since their financial capital to conduct own R\&D operations is relatively limited. All in all, in the case of SMEs the focus in terms of innovation indicators should be on the positive outcomes, which are related to the operational capability and the working environment (Laforet, 2013).

\section{Methodology}

For the purposes of this study, a secondary data analysis and a desk research together with descriptive and comparative analysis have been performed. The benefits and importance of using secondary data analysis is highlighted by Trinh (2018). The author points out the positive results of secondary data collection. Amongst the most efficient benefits are mentioned the financial and the logistical hurdles related to primary data collection. Also, secondary data comprises the "significant efforts" of organizations, state or national institutions to provide large and economical datasets (Trinh, 2018).

In defining its Europe 2020 strategy the European Commission launched in October 2013 the EU2020 Innovation Indicator in order to establish metrics that determine the innovation outputs and outcomes. As mentioned previously, most of the focus has fallen on the R\&D

DOI: $10.2478 /$ picbe-2020-0015, pp. 149-158, ISSN 2558-9652| Proceedings of the $14^{\text {th }}$ International Conference on Business 
activities, which represent a sign of output innovation with multiple benefits for the industry. However, in recent years, many approaches pursued the development of indicators that could refer to the outcomes and the relationships created between organizations. In this sense, the EU2020 Innovation Indicator provides adequate information that serves as metric for both outputs and outcomes (Janger et al., 2017).

For the purposes of this paper, the reports published by the European Commission in the past five years, namely the European Innovation Scoreboard (from years 2015, 2016, 2017, 2018 and 2019) and the Regional Innovation Scoreboard 2019 have been analyzed. The data has been selected by taking into consideration several factors, amongst which special importance was placed on the time of publishing the data, the reliability of the data in the published research and the place of publishing and adequacy of data. In this sense, the European Innovation Scoreboard (EIS) is a report that presents the innovative activity of the EU Member States. For the past five years that have been analyzed, EIS defined a computed average of 26 indicators. The Regional Innovation Scoreboard (RIS) complements EIS and approaches the innovation matter at a regional level, while focusing on 17 indicators for the year 2019, thus assessing the "performance of innovation systems across 238 regions of 23 EU Member States" (RIS 2019, published by the European Commission).

Therefore, this study is based entirely on the data provided by these reports. A comparative analysis has been performed on the secondary data provided by these reports in order to establish the measurement framework for innovation in European countries and metrics used in order to assess innovation. In all these reports, Romania is highlighted as a modest innovator, with the lowest score amongst all countries from European Union. Therefore, this has emerged as the biggest concern of this paper and has concluded in depicting the main weaknesses of Romanian small and medium enterprises that conducted to this result. The focus has fallen on depicting the main indicators provided by these reports and their applicability in the context of innovative SMEs for the particular case of Romania.

\section{Results and discussions}

The reports analyzed in this paper define four categories of indicators that can be used as metrics to measure innovation, namely: framework conditions, investments, innovation activities and impacts.

The European Innovation Scoreboard (EIS) reports from the last five years identify a general measurement framework that comprises three types of indicators and eight innovation dimensions. For 2015 and 2016, the innovation framework proposed by the European Commission can be represented as follows, using the data from the EIS reports:

\begin{tabular}{|c|c|c|}
\hline \multicolumn{3}{|c|}{ Enablers } \\
\hline Human resources & Research systems & Finance and support \\
\hline \multicolumn{3}{|c|}{ Firm activities } \\
\hline Firm investments & Linkages and entrepreneurship & Intellectual assets \\
\hline \multicolumn{3}{|c|}{ Outputs } \\
\hline Intellectual assets & Innovators & Economic effects \\
\hline
\end{tabular}

Table 1. Innovation framework - main indicators and dimensions

Source: Author's own adaptation based on EIS reports data (2015-2016)

DOI: $10.2478 /$ picbe-2020-0015, pp. 149-158, ISSN 2558-9652| Proceedings of the $14^{\text {th }}$ International Conference on Business Excellence 2020 
The reports of the following years, namely 2017, 2018 and 2019 propose a different approach and by consequence, a different innovation framework. The updated framework identifies four types of indicators and ten innovation dimensions. This framework can be represented as follows:

\begin{tabular}{|c|c|c|}
\hline \multicolumn{3}{|c|}{ Framework conditions } \\
\hline Human resources & Attractive research systems & Innovation-friendly environment \\
\hline \multicolumn{3}{|c|}{ Investments } \\
\hline Finance and support & Firm investments \\
\hline \multicolumn{3}{|c|}{ Innovation activities } \\
\hline Linkages & Intellectual assets \\
\hline \multicolumn{3}{|c|}{ Impacts } \\
\hline Employment impacts & Sales impacts \\
\hline
\end{tabular}

Table 2. New Innovation framework - main indicators and dimensions

Source: Author's own adaptation based on EIS reports data (2017-2019)

In addition, the Regional Innovation Scoreboard 2019 (RIS 2019) addresses the performance of EU countries clustered in regions and describes only 17 indicators out of a computed average of 26 indicators present in the European Innovation Scoreboard reports from the past five years. The report contains a detailed overview of the indicators and the corresponding performance of the regions.

The data considered for the European reports is represented by the statistics provided both by Eurostat and by other international sources such as OECD (Organization for Economic Cooperation and Development) and United Nations. Considering that the focus of this paper is represented by innovation applied in small and medium enterprises, we have considered the following indicators from the RIS 2019 to be representatives for SMEs innovative efforts:

\begin{tabular}{|c|c|c|}
\hline \multicolumn{3}{|c|}{ Innovation activities } \\
\hline $\begin{array}{c}\text { SMEs with product or } \\
\text { process innovations }\end{array}$ & $\begin{array}{c}\text { SMEs with marketing or } \\
\text { organizational innovations }\end{array}$ & SMEs innovating in-house \\
\hline \multicolumn{2}{|c|}{ Linkages } \\
\hline \multicolumn{3}{|c|}{ Innovative SMEs collaborating with others } \\
\hline
\end{tabular}

Table 3. Innovation indicators of relevance for SMEs

Source: Author's own adaptation based on RIS report data (2019)

The indicators mentioned above have been selected due to their impact on SMEs activities. Another criterion was Romania's own score and rank as an innovator when compared to the other countries from Europe. In the RIS 2019 report, Romania is highlighted as a modest innovator both overall as well as when measuring the indicators mentioned. In the report, Romania appears to be a negative outlier and together with the regions described as modest innovators, the overall performance score is below 50\% when compared to the EU average. The report presents as well a comparison between the eight regions of Romania. 


\begin{tabular}{|c|c|c|c|}
\hline Indicators & Romanian region & $\begin{array}{l}\text { Performance } \\
\text { rank for } \\
\text { Romanian } \\
\text { region }\end{array}$ & $\begin{array}{c}\text { European } \\
\text { performance rank } \\
\text { (for modest } \\
\text { innovators) } \\
\end{array}$ \\
\hline \multirow{8}{*}{$\begin{array}{l}\text { - SMEs with product or } \\
\text { process innovations } \\
\text { - SMEs with marketing or } \\
\text { organizational innovations } \\
\text { - SMEs innovating in-house } \\
\text { - Innovative SMEs } \\
\text { collaborating with others }\end{array}$} & North-West & 29,7 & \multirow{2}{*}{36} \\
\hline & Center & 27,3 & \\
\hline & North-East & 21,5 & \multirow{3}{*}{35} \\
\hline & South-East & 22,1 & \\
\hline & South- Muntenia & 18,4 & \\
\hline & South-West- Oltenia & 14,3 & 33 \\
\hline & West & 32,8 & \multirow{2}{*}{26} \\
\hline & Bucharest-Ilfov & 51,6 & \\
\hline
\end{tabular}

Table 4. Romanian innovation performance score reported to European average

Source: Author's own adaptation based on RIS report data (2019)

Therefore, a main trend can be deducted from this data, namely that small and medium enterprises in Romania are not focused on innovative approaches and there is a limited effort in both technological and non-technological activity. This is reflected in the lack of innovation in both product and process related endeavors, as well as internal innovation in SMEs. Also, their engagement in product and process innovation is relatively low compared to other EU countries.

Another deduction from the data published in the report is the importance that should be placed on the collaboration between SMEs. The trends in this respect are ascending, the București-Ilfov region being considered a moderate innovator, which can be considered a strength. In this sense, an increase in business collaboration and diversity of information sources is highly recommended.

In terms of weaknesses, this study identifies the low share of small and medium innovative enterprises in Romania. This descriptive analysis concludes that Romania is at the bottom of innovative countries, especially when compared to the Western European countries.

\section{Conclusion}

Overall, the European Commission European Innovation Scoreboard reports and its complement Regional Innovation Scoreboard 2019 place Romania as a modest innovator, with scarce innovative approaches, especially when related to SMEs endeavors. Both in terms of product and process, as well as in the market orientation, used as indicators of measuring innovation performance, Romania is constantly positioned on the last places. Although placed on a higher rank in regards with collaboration between enterprises as innovator, this is of little importance in the overall picture.

Therefore, this is a main challenge that Romania has to focus on, namely investing in innovative endeavors in order to increase economic growth and provide competitive advantage. In this sense, the promotion and encouragement of collaborative approaches and knowledge can be a possible facilitator for the situation. Moreover, an additional focus on research activities can be initiated, due to the low level of technological advancements inferred from the report data.

All in all, this study provides several insights that have emerged from the descriptive and comparative analysis performed and can be used for future research. Also, this paper analyzes the main trends and weaknesses in Romanian SMEs and highlighted as well the connection between 
entrepreneurship and the need for innovation. In addition, the construction and implementation of an entrepreneurial culture can be another area of focus that could create the premises of an environment where the innovation indicators can be successfully applied, in order to create economic growth and sustainable development.

\section{References}

Cavdar, S. C. \& Aydin, A. D. (2015). An Empirical Analysis about Technological Development and Innovation Indicators. Procedia - Social and Behavioral Sciences, 195, 1486-1495.

Cheng, C. C. J. \& Huizingh, E. K. R. E. (2014). When Is Open Innovation Beneficial? The Role of Strategic Orientation. Journal of Product Management, 31 (6), 1235-1253.

De Marco, C. E., Martelli, I. \& Di Minin, A. (2020). European SMEs' engagement in open innovation When the important thing is to win and not just to participate, what should innovation policy do?. Technological Forecasting \& Social Change, 152, 119843.

Dodescu, A. \& Chirilă, L. V. (2012). Regional innovation governance in the context of European integration and multi-level governance challenges. A Case Study of North-West Region of Romania. Procedia Economics and Finance, 3, 1177-1184.

Dziallas, M. \& Blind, K. (2019). Innovation indicators throughout the innovation process: An extensive literature analysis. Technovation, 80, 3-29.

Edwards-Schachter, M. (2018). The nature and variety of innovation. International Journal of Innovation Studies, 2, 65-79.

European Commission. (2019). European Innovation Scoreboard 2019 - Methodology Report. Maastricht Economic and Social Research Institute on Innovation and Technology MERIT.

European Commission. (2019). Regional Innovation Scoreboard 2019. Luxembourg: Publications Office of the European Union, 2019.

Fonseca, L.M., Domingues, J. P., \& Dima, A.M. (2020). Mapping the sustainable development goals relationships. Sustainability, 12(8), 3359, Special Issue: Sustainable Business Models and Innovation in the Knowledge Economy/ Business Revolution in the Digital Era - Selected Papers from the $13^{\text {th }}$ and $14^{\text {th }}$ International Conference on Business Excellence.

Forsman, H. (2011). Innovation capacity and innovation development in small enterprises. A comparison between the manufacturing and service sectors. Research Policy, 40, 739-750.

Gault, F. (2018). Defining and measuring innovation in all sectors of the economy. Research Policy, 47, 617-622.

Genc, E., Dayan, M. and Genc, O. F. (2019). The impact of SME internationalization on innovation: The mediating role of market and entrepreneurial orientation. Industrial Marketing Management, 82, 253-264.

Haneda, S. \& Ito, K. (2018). Organizational and human resource management and innovation: Which management practices are linked to product and/or process innovation?. Research Policy, 47, 194-208.

Hashi, I. \& Stojcic, N. (2013). The impact of innovation activities on firm performance using a multi-stage model: Evidence from the Community Innovation Survey 4. Research Policy, 42, 353-366. 
Hervas-Oliver, J., Garrigos, J. A. \& Gil-Pechuan, I. (2011). Making sense of innovation by R\&D and non-R\&D innovators in low technology contexts: A forgotten lesson for policy makers. Technovation, 31, 427-446.

Janger, J., Schubert, T., Andries, P., Rammer, C. \& Hoskens, M. (2017). The EU 2020 innovation indicator: A step forward in measuring innovation outputs and outcomes? Research Policy, 46, 30-42.

PICBE $\mid 158$

Kardos, M. (2012). The Relationship between Entrepreneurship, Innovation and Sustainable Development. Research on European Union Countries. Procedia Economics and Finance, 3, 1030-1035.

Kramer, J., Marinelli, E., Iammarino, S. \& Diez, J. R. (2011). Intangible assets as drivers of innovation: Empirical evidence on multinational enterprises in German and UK regional systems of innovation. Technovation, 31, 447-458.

Laforet, S. (2013). Organizational innovation outcomes in SMEs: Effects of age, size, and sector. Journal of World Business, 48, 490-502.

Pradhan, R. P., Arvin, M. B., Bahmani, S. \& Bennett, S. E. (2017). The innovation- growth link in OECD countries: Could other macroeconomic variables matter?. Technology in Society, 51, 113-123.

Talmaciu, M. (2012). Considerations regarding the development of Romanian regional economies through innovation and entrepreneurship. Procedia Economics and Finance, 3, 914-920.

Trinh, Q. (2018). Understanding the impact and challenges of secondary data analysis. Urologic Oncology:Seminars and Original Investigations, 36, 163-164.

Turro, A., Urbano, D. \& Peris-Ortiz, M. (2014). Culture and innovation: The moderating effect of cultural values on corporate entrepreneurship. Technological Forecasting \& Social Change, 88, 360-369.

Wu, C. \& Huarng, K. (2015). Global entrepreneurship and innovation in management. Journal of Business Research, 68, 743-747. 